Revista lus et Praxis, Año 25, № 2, 2019, pp. 433 - 458

ISSN 0717 - 2877

Universidad de Talca - Facultad de Ciencias Jurídicas y Sociales

El caso del despido indirecto y la suspensión del plazo:

¿Interpretación o creación judicial del derecho?

Luis A. Silva Irarrázaval

Trabajo recibido el 6 de noviembre de 2018 y aprobado el 9 de marzo de 2019

\title{
El caso del despido indirecto y la suspensión del plazo: ¿Interpretación o creación judicial del derecho?
}

\section{INTERPRETING OR CREATING THE LAW? A CRITICAL APPROACH TO THE JUDICIAL UNDERSTANDING OF SECTION 171 OF THE LABOR CODE}

Luis A. Silva Irarrázaval

ResUMEN

En este artículo se sostiene críticamente que la aplicación que los tribunales hacen de la regla del artículo 168, inciso final, del Código del Trabajo al supuesto del despido indirecto (artículo 171), no es resultado de una tarea hermenéutica, sino creadora del derecho. Al amparo del principio protector del derecho laboral, los jueces modifican la valoración de los supuestos fácticos hecha por el legislador al momento de dictar la ley. De este modo, los jueces se erigen ellos mismos en legisladores.

\section{ABSTRACT}

The purpose of this paper is to analyze a Labor case law which consists in the extension of a rule of section 168 final paragraph of the Labor Code to a different hypothetical, that of section 171. It states that judicial enforcement of section 168's rule to those situations covered by section 171 ensues not as the product of judicial interpretation but as an outcome of judicial activism. Under the claim that they are applying a central principle of Labor Law, judges alter legislator's intent by attaching a different juridical value to factual premises underlying the legal text. By this fashion, judges become legislators themselves.

PalABRAs CLAVE

Integración del derecho; interpretación de la ley; despido laboral

KEY WORDS

Integration of the law; statutory interpretation; dismissal

\section{Introducción}

El debate acerca de la aplicación de la regla del artículo 168, inciso final, del Código del Trabajo (CdT) al supuesto contemplado en el artículo 171

\footnotetext{
* Profesor de Derecho Constitucional de la Universidad de los Andes, Mons. Álvaro del Portillo 12.455, Las Condes, Santiago, Chile. Correo electrónico: Isilva@uandes.cl. Doctor en Derecho. Este trabajo se enmarca en el proyecto Fondecyt Regular № 1161334. Agradezco los comentarios al borrador de este artículo de los profesores Rodrigo Pessoa, Juan Pablo Severin, Alfredo Sierra, Raúl Bertelsen, Claudio Alvarado y Fernando Contreras; de Allison Pastén, una alumna promisoria, y la ayuda de Isidora Casas del Valle, tesista.
} 
CdT, replica a pequeña escala un problema perenne del derecho: ¿deben los jueces hacer justicia al precio de ignorar la intención del legislador o deben los jueces obedecer la intención del legislador al precio de ignorar la justicia? El debate en este caso es el siguiente: si acaso los jueces pueden aplicar la regla de suspensión de caducidad del plazo de la acción de indemnización por despido injustificado, que la ley otorga al trabajador que es despedido, a la situación del trabajador que se autodespide, para el que la ley no dispone este beneficio.

En este estudio, que abarca sentencias dictadas entre 2007 y 2018, se analiza críticamente la jurisprudencia que extiende el beneficio de la suspensión del artículo 168, inciso final, CdT al supuesto del artículo 171 CdT, para concluir que en realidad los jueces llegan a ese resultado no como consecuencia de interpretar la ley, sino de crearla. El juez laboral entendería que la inexistencia del beneficio de la suspensión del plazo para los trabajadores que se autodespiden configura una laguna axiológica que está autorizado a colmar, integrando así el derecho con una norma jurídica ad hoc.

La creación de reglas ad hoc por parte del juez puede ser una posibilidad generalmente admitida en el contexto del derecho laboral. Especialmente será así entre quienes comparten ciertas premisas iusfilosóficas. Por ello es que este análisis crítico no se dirige principalmente a discutir si el trabajador que se autodespide debería gozar de una regla similar a la que tiene el trabajador despedido, sino a poner las bases para un cuestionamiento de las premisas en que se asienta esa tendencia favorable a la creación judicial de normas.

Finalmente, se sugiere que el juez laboral no debería aplicar la regla del artículo 168, inciso final, al caso del artículo 171, porque al hacerlo estaría corrigiendo lo dispuesto por el legislador, erigiéndose él mismo en legislador. Esto, que quizá en el marco de una determinada concepción del derecho laboral representaría la conducta exigible a los jueces, ofrece sin embargo un problema desde la perspectiva del diseño institucional, que descansa sobre la distinción entre los ámbitos jurídico (judicial) y político (legislativo). Es la salvaguarda de la antedicha distinción lo que motiva al final del artículo una lectura crítica de esta específica jurisprudencia laboral.

El desarrollo del argumento se estructura en cinco secciones luego de esta introducción. La primera (2) explica el caso e intenta mostrar su carácter controvertido. La segunda (3) busca probar cuál fue la intención del legislador, para luego (4) sostener que la actividad del juez laboral no puede calificarse como interpretación de la ley. En la sección siguiente (5), se concluye que la actividad del juez en este caso sustituye la voluntad del legislador y se explica por qué esto podría ser considerado críticamente. Finalmente (6), se enuncian las conclusiones. 


\section{La problemática cuestión del plazo de caducidad en el despido indirecto}

En esta sección no interesa indagar en la corrección de los argumentos que se debaten en la jurisprudencia y en la doctrina nacional, sino solo mostrar que existe un debate. La controversia en torno a esta cuestión, tanto en la jurisprudencia como en la doctrina, refleja la existencia de buenas razones en favor de las dos posturas encontradas ${ }^{1}$. Esta sola comprobación debería reforzar la cautela de los operadores jurídicos a la hora de enfrentar las propias posiciones con las contrarias.

\subsection{Antecedentes}

El artículo 168, inciso final, CdT dispone: "El plazo [de 60 días que tiene el trabajador despedido para recurrir al tribunal a fin de que declare el despido injustificado, indebido o improcedente] se suspenderá cuando, dentro de éste, el trabajador interponga un reclamo (...) ante la Inspección del Trabajo respectiva (... $)^{\prime \prime 2}$. El artículo 171, por su parte, dispone en el inciso primero: "Si quien incurriere en las causales de los números 1, 5 ó 7 del artículo 160 fuere el empleador, el trabajador podrá poner término al contrato y recurrir al juzgado respectivo, dentro del plazo de sesenta días hábiles, contado desde la terminación, para que éste ordene el pago de las indemnizaciones (...)". No existe en el caso del artículo 171 disposición alguna sobre la suspensión de este plazo.

Hoy en día es frecuente que, al terminar la relación laboral mediante el despido indirecto, los trabajadores recurran ante la Corte Suprema contra la sentencia que declara la caducidad del plazo para demandar la nulidad del despido y las consiguientes indemnizaciones ${ }^{3}$.

La infracción de derecho invocada en los recursos es el error en el cómputo del plazo de caducidad de la acción, que es de sesenta días, y que resulta

\footnotetext{
${ }^{1}$ No conocemos un pronunciamiento oficial de la Inspección del Trabajo respecto del punto en debate. Sin embargo, es significativo que, en un artículo doctrinal sobre el despido indirecto, defina lo siguiente: "El artículo 171 del Código del Trabajo, señala este plazo [de sesenta días] para que el trabajador concurra al juzgado. Este plazo no permite su suspensión, como sí lo señala el inciso final del artículo 168 Código del Trabajo, mientras se tramita el reclamo ante la Inspección del Trabajo, por lo que el plazo de los 60 días hábiles para recurrir al Juzgado no admite prórroga de ninguna clase": InSPECCIÓN DeL TRABAjO (2011), p. 31. Por otra parte, concluimos que la constitucionalidad del artículo 171 no ha sido desafiada, porque después de revisar la jurisprudencia del Tribunal Constitucional, no encontramos ningún pronunciamiento sobre la cuestión.

2 Esta disposición fue incorporada al artículo 168 CdT por la Ley № 19.447, de 1996.

${ }^{3}$ Antes de la reforma procesal laboral (Ley № 20.087, de 2006), lo habitual era que se presentaran recursos de casación en el fondo. Después de la reforma, se usa el recurso de queja. Por supuesto que también en muchos casos el juicio termina en las Cortes de Apelaciones.
} 
de ignorar la suspensión de este por la interposición de un reclamo ante la Inspección del Trabajo. Esto evidentemente incide en lo sustancial del fallo, porque de haberse considerado la suspensión en el cómputo del plazo, la acción habría sido interpuesta oportunamente. Lo que el juez de letras debió haber hecho, según los recurrentes, fue contabilizar el plazo aplicando la regla del inciso final del artículo $168 \mathrm{CdT}$.

Los tribunales superiores de justicia han acogido en repetidas ocasiones lo demandado por el trabajador. En estos casos, la aplicación de la regla sobre suspensión del plazo del artículo 168, inciso final, al despido indirecto es inequívoca: "el plazo de sesenta días hábiles contemplado en el inciso primero del artículo $171 \mathrm{CdT}$ se suspende, cuando dentro de éste el trabajador interpone un reclamo administrativo" ${ }^{\prime 4}$.

\subsection{La jurisprudencia}

La jurisprudencia de la Corte Suprema confirma que la cuestión es problemática. Antes de la reforma procesal laboral de 2006, la corte ni siquiera admitía que la suspensión de la caducidad del plazo en el caso del autodespido fuera una cuestión sujeta a interpretación. El fundamento en sus sentencias de casación era claro: para los intérpretes, la intención del legislador se expresaba inequívoca en el texto de la ley en el sentido de distinguir entre el despido patronal y el despido indirecto, en función de la voluntad del trabajador que interviene en el segundo caso $^{5}$.

Con la reforma procesal laboral, la controversia se planteó ante la Corte Suprema a través del recurso de queja. La primera sentencia de que tenemos noticia es de marzo de $2014^{6}$. Allí, los jueces rechazaron el recurso por no ser la vía procesal idónea para cuestionar el resultado de un trabajo de interpretación debidamente fundamentado: el argumento de los jueces recurridos que concluyó que el plazo de caducidad de la acción de despido indirecto no se suspende fue resultado de un "proceso intelectual [en que] los sentenciadores ejercieron sus facultades privativas"

\footnotetext{
${ }^{4}$ Por todas, Corte Suprema, rol № 5780-2015, de 21 de enero de 2016, cons. $2^{\circ}$ (sentencia de reemplazo).

${ }_{5}^{5}$ Por ejemplo, Corte Suprema, rol № 692-2008, de 8 de abril de 2008; Corte Suprema, rol № 3502007, de 28 de noviembre de 2007. Ver nota 38.

${ }^{6}$ Corte Suprema, rol № 17325-2013, de 11 de marzo de 2014.

7 Corte Suprema, rol № 17325-2013, de 11 de marzo de 2014, cons. $6^{\circ}$. No obstante, los ministros Cisternas y Chevesich votaron en contra y estuvieron por anular de oficio el procedimiento porque el plazo debió haberse suspendido. A la luz del cambio que experimentará la jurisprudencia en este
} 
Con la sentencia "Serrano con Transportes Artisa Limitada", la Corte Suprema inauguró un periodo de ambigüedad respecto de cómo debe entenderse el problema de la suspensión del plazo de la acción en el autodespido ${ }^{8}$. En defensa de la finalidad del recurso de queja y, simultáneamente, del legítimo ámbito de discrecionalidad de los jueces del fondo para interpretar la ley, la Corte Suprema rechazó la petición de anular la sentencia por la vía disciplinaria. Sin embargo, decidió de oficio dejar sin efecto las resoluciones del juez de letras y de la Corte de Apelaciones que declararon la extinción del plazo para accionar, porque una interpretación acorde con el principio pro operario así lo ordenaría9 .

En diciembre del mismo año, la Corte Suprema rechazó un recurso de queja, porque la interpretación que los jueces recurridos hicieron del artículo 171 en relación con el inciso final del artículo 168, fue la de una "omisión que parece razonable, ya que en el caso del auto despido es el propio trabajador quien toma la decisión de desvincularse", y esta interpretación, aunque fuera errada, dice la sentencia, no puede calificarse como una falta o abuso grave ${ }^{10}$. Lo curioso de esta sentencia es que, a diferencia de las dos que le preceden, no invalidó de oficio lo obrado por los jueces inferiores, respaldando así la interpretación que descarta la suspensión del plazo de la acción del artículo $171^{11}$.

A comienzos de 2016, la Corte Suprema acogió un recurso de unificación de jurisprudencia. Allí estableció que la regla del artículo 168, inciso final, aplica también en el caso del artículo 171, porque el despido patronal y el despido indirecto son semejantes "en todo orden de materias"12. Sin embargo, esto no sirvió para predecir la posición de la corte en los casos que siguieron después ${ }^{13}$.

punto, resulta significativo que la ministra Gloria Ana Chevesich, quien se incorporó a la Corte Suprema el 2 de agosto de 2013, haya redactado el voto.

${ }^{8}$ Corte Suprema, rol No 4317-2014, de 12 de mayo de 2014.

${ }^{9}$ Corte Suprema, rol № 4317-2014, de 12 de mayo de 2014, cons. $2^{\circ}$ de la resolución de oficio.

${ }^{10}$ Corte Suprema, rol No 24426-2014, de 22 de diciembre de 2014, cons. $2^{\circ}$.

11 La ministra Chevesich votó en contra y estuvo por acoger el recurso de queja. En Corte Suprema, rol No 13503-2015, de 29 de octubre de 2015, la corte retomará el esquema de rechazar la queja pero actuar de oficio, con votos en contra de la ministra Muñoz y el ministro Correa, ambos de la idea de rechazar la queja, pura y simplemente.

12 Corte Suprema, rol № 5780-2015, de 21 de enero de 2016. Ver nota 40.

${ }^{13}$ En efecto, en Corte Suprema, rol № 41024-2016, de 24 de agosto de 2016, se acogió el recurso de queja, con prevención de la ministra Muñoz, quien estuvo por rechazar la queja, pero, en cambio, dejar sin efecto de oficio las resoluciones. En Corte Suprema, rol No 73777-2016, de 17 de noviembre de 2016, se rechazó el recurso de queja, pero de oficio se invalidaron las resoluciones judiciales que declararon extinto el plazo sin reconocer su suspensión. En Corte Suprema, rol № 87910-2016, de 22 de diciembre de 2016, se repitió el esquema de la sentencia precedente. Significativa resulta la decisión de la ministra Gloria Ana Chevesich, en Corte Suprema, rol № 73777-2016, de 17 de noviembre de 
La última sentencia que conocemos, "Obrali con Proyecto 54 S.A.", rechazó el recurso de queja interpuesto contra los jueces que declararon la extinción del plazo sin aplicar la regla del artículo 168, inciso final, al autodespido ${ }^{14}$. Como otras veces antes, los sentenciadores afirmaron que "el proceso de interpretación de la ley que llevan a cabo los juzgadores en cumplimiento de su cometido no puede ser revisado por la vía del recurso de queja, porque constituye una labor fundamental, propia y privativa de los jueces, a menos que en dicho proceso se advierta de forma manifiesta un razonamiento abusivo o que atente contra las reglas del buen uso de la razón en la construcción de los argumentos interpretativos, lo que no se verifica en la especie ${ }^{\prime \prime 15}$.

\subsection{La doctrina}

La cuestión acerca de la extensión de la regla de suspensión del plazo del artículo 168 al 171 es controvertida entre los autores. Después de la publicación de la Ley $N^{\circ} 19.447$, en febrero de 1996, la doctrina se dividió. La línea divisora resulta de la distinta valoración de los supuestos fácticos del despido indirecto en relación con los del despido patronal. Grosso modo, quienes estiman que entre ambas no median diferencias que pudieran justificar una forma distinta de computar el plazo, consideran que la ley adolece de un defecto que debe ser corregido por los jueces ${ }^{16}$. En cambio, quienes consideran que hay motivos razonables para justificar una regla sobre cómputo del plazo para el trabajador despedido distinta del que se autodespide, concluyen que los jueces deben abstenerse de corregir la ley ${ }^{17}$.

\section{La intención del legislador}

Es un hecho indiscutido que el artículo 168 contiene en su texto una regla que el artículo 171 no contiene. La cuestión es por qué. En otras palabras, ¿Cómo debe entenderse esta diferencia entre los dos artículos? Esta pregunta,

2016, de hacer constar "que su postura actual difiere de la asumida en el recurso de queja número de ingreso 41.024-2016 [esto es, acoger el recurso de queja], por haber arribado a la conclusión que (...) lo que motivó este recurso es una decisión que los jueces recurridos adoptaron interpretando las normas legales que rigen el asunto sometido a su conocimiento".

${ }^{14}$ Corte Suprema, rol № 34306-2017, de 23 de agosto de 2017.

15 Corte Suprema, rol № 34306-2017, de 23 de agosto de 2017, cons. 5. Hubo prevención del ministro Blanco, quien estuvo por rechazar la queja, pero dejar sin efecto de oficio las resoluciones.

16 Gamonal (1998), p. 205; Nadal (2004), p. 431; Gamonal, (2016); Caamaño (2016); Vergara (2016).

17 Mella (2001), p. 99; Benavides (2009), p. 140; Dighero (2016). También están los que no se pronuncian: ThaYer y Novoa (2003), pp. 115-118; Barahona (2010), pp. 102-105. 
en el fondo, está apelando a la racionalidad de la norma y la intención del legislador: ¿es una diferencia realizada intencionalmente o se trata de una omisión involuntaria? ${ }^{18}$.

La actividad de interpretar la ley debiera asumir que el legislador es un agente racional porque, finalmente, la autoridad de las leyes que dicta descansa en la premisa de que es "un tipo de institución capaz de actuar responsablemente por el bien común"19. De allí que, como Ekins señala, haya que ser muy cautos a la hora de concluir que el legislador ha actuado de manera irresponsable, $v$. gr., que haya omisiones involuntarias ${ }^{20}$. Y es que, al afirmar que el legislador ha incumplido su deber, se debilitan los cimientos en que se sostiene la legitimidad de la legislación parlamentaria.

En principio, la respuesta a la pregunta de por qué el artículo 171 carece de una regla como la del inciso final del artículo 168, es que se trata de una omisión intencional. Por supuesto que el legislador comete errores, y bien podría ser que en este caso se tratara de una omisión involuntaria ${ }^{21}$, pero esto tendría que demostrarse ${ }^{22}$. No obstante, existen buenas razones para inferir que la omisión de la regla en el artículo 171 es intencional. La existencia de estas razones se induce, en primer lugar, de la diferente evolución legislativa del despido patronal y del despido indirecto; en segundo lugar, de las diferencias que la legislación vigente hace entre ambas formas de terminación de la relación laboral.

\footnotetext{
${ }^{18}$ Esta pregunta es pertinente aun en el caso en que se entendiera el despido indirecto como una especie de despido injustificado. Ello porque la relación de género a especie no elimina de por sí las diferencias entre uno y otro caso. Luego, a menos de que junto con la propuesta de entender el despido indirecto como una forma de despido injustificado se esté postulando la eliminación de todas las diferencias absolutamente, subsistirá la necesidad de explicar por qué el principio in dubio pro operario exige eliminar la diferencia respecto de la regla de suspensión del plazo y no la eliminación de las otras diferencias que la ley establece entre el despido patronal y el indirecto, o entre las otras formas de despido injustificado. Este es el desafío que debería abordar FariÑA (2014), cuando postula la homologación entre el despido constructivo y el despido patronal.

19 EkINs (2012), p. 245.

20 EKINS (2012), p. 245.

${ }^{21}$ Donde dice omisiones, debe entenderse que resulta una laguna jurídica. Pero Perelman (1979), p. 47, advierte que "no debe hablarse de lagunas del Derecho sólo porque las tentativas de interpretar la ley no dan resultados satisfactorios. Pues las controversias jurídicas concretas demuestran que, muy frecuentemente, se constata un desacuerdo entre los intérpretes, cuestión que entraña, de por sí, un desacuerdo en cuanto a la existencia o inexistencia misma de la laguna".

22 Gamonal (1998), p. 205, cree que la inexistencia de una regla de suspensión del plazo de caducidad para el despido indirecto "se trata de una omisión involuntaria del legislador y que el precepto en comento (el inciso final del artículo 168) es plenamente aplicable al despido indirecto". Sin embargo, no ofrece prueba alguna para sustentar su opinión.
} 


\subsection{La evolución legislativa}

En toda su historia, el despido indirecto ha sido objeto de, al menos, cuatro modificaciones legales y nunca se ha considerado una regla que suspenda el plazo de caducidad de la acción para demandar la nulidad del despido ${ }^{23}$. Por lo tanto, desde la perspectiva de la evolución de nuestra legislación laboral, no parece responsable asumir que se trata de omisión involuntaria sin un serio examen previo de la historia.

Una reflexión particular sobre la historia de la Ley № 19.447, que introdujo la regla sobre suspensión del plazo en el artículo 168, inciso final, CdT, permite inferir que, para el legislador de 1996, las diferencias entre el despido patronal y el despido indirecto sí justificaban un tratamiento diferente en el cómputo del plazo ${ }^{24}$. Esta conclusión nace del hecho de que entre los antecedentes de la discusión parlamentaria acerca de la suspensión del plazo, no se halla ni una sola referencia al supuesto del artículo 171.

Uno de los objetivos del proyecto de ley presentado por el gobierno era optimizar el acceso de los trabajadores a la justicia laboral, mediante una mejor articulación entre los tribunales de justicia y la Inspección del Trabajo ${ }^{25}$. Para alcanzarlo, se vio conveniente incentivar a los trabajadores para que reclamaran ante la Inspección del Trabajo, ya que muchos casos podrían solucionarse en dicha instancia, contribuyendo así a descongestionar el trabajo de los jueces ${ }^{26}$. La suspensión del plazo de caducidad de la acción para recurrir ante los tribunales de justicia es precisamente uno de esos incentivos ${ }^{27}$.

¿Por qué la suspensión del plazo fue un incentivo pensado solo para el trabajador despedido y no para el que se autodespide? Los registros de la discusión parlamentaria no permiten responder directamente a esta pregunta porque, como se dijo más arriba, omiten toda referencia al supuesto del artículo 171. La pregunta entonces debería ser por qué el despido indirecto estuvo al margen

\footnotetext{
${ }^{23}$ Para un detalle de la historia legislativa del despido indirecto, BARAHONA (2010), pp. 24-43.

${ }^{24}$ En este sentido argumentó la sentencia Corte Suprema, rol № 350-2007, de 28 de noviembre de 2007, cons. $6^{\circ}$ : "[de la historia de la ley se deduce] que el legislador, en el contexto de modificaciones normativas tendientes a mejorar la situación de los dependientes, tanto en un ámbito sustantivo como también adjetivo, no alteró mayormente la institución del despido indirecto, menos en un sentido procedimental como lo es la forma de determinación del plazo de caducidad, haciéndose patente, en ese punto, la diferencia entre ambos preceptos".

25 Historia de la Ley $N^{0} 19.447$, p. 5.

${ }^{26}$ Historia de la Ley $N^{\circ} 19.447$, p. 29.

27 Esta finalidad es coherente con la naturaleza de la caducidad, que es la de una sanción jurídica, GamONal (1998), p. 204, y manifiesta su carácter excepcional: los plazos de caducidad no se suspenden, a menos que la ley señale lo contrario [GamONAL (1998), p. 203].
} 
de la discusión acerca de los incentivos para que los trabajadores concurrieran a la instancia administrativa antes que a la judicial.

El motivo que nos parece más plausible para explicar esta omisión es el lugar preeminente que el despido patronal ha tenido en el derecho del trabajo y que, "por el cúmulo de elementos sociales, jurídicos y éticos que se entremezclan en torno suyo" ${ }^{\prime 28}$, concentra naturalmente la atención de los legisladores. Esta circunstancia implica de manera tácita que se lo ha entendido como un supuesto diferente al del autodespido. La literatura de la época en que se dictó la Ley $N^{\circ} 19.447$-y hasta el día de hoy-califica el despido patronal y el despido indirecto como formas de terminar el contrato de trabajo por voluntad de una de las partes (causales subjetivas de terminación), cuando se verifican una o más causales de caducidad. Pero las diferencia indicando que la primera termina por voluntad del empleador y la segunda por voluntad del trabajador ${ }^{29}$.

En las coordenadas del legislador del año 1995, el despido indirecto habría quedado al margen de la discusión por carecer de ese elemento que explica la centralidad del despido en el derecho laboral: la unilateralidad patronal. La figura estaba entonces tan distante del despido patronal en la mente del legislador que la omisión en este caso no podría calificarse simplemente como involuntaria. $\mathrm{Al}$ menos, los antecedentes disponibles no permiten asumirlo ${ }^{30}$.

\subsection{La legislación vigente}

Otra línea de argumentación para demostrar que la inexistencia de una regla de suspensión del plazo para el autodespido es intencional se apoya en la respuesta con que la ley se ajusta a las semejanzas y diferencias fácticas que hay entre el despido patronal y el despido indirecto. En efecto, la existencia de distinciones fácticas entre el despido patronal y el despido indirecto no debe llevar a pensar que se trata de dos supuestos completamente diferentes. De hecho, existen varias semejanzas entre ambos que justifican un mismo tratamiento legal; v. gr. las mismas causales del despido injustificado (aunque no todas) operan en

\footnotetext{
${ }^{28}$ ThAYer y NOVOA (1989), p. 405. Resulta significativo que William Thayer integrara la Comisión de Trabajo y Previsión Social del Senado durante la tramitación de la Ley № 19.447.

29 Thayer y Novoa (1989), pp. 368, 386 y ss., 439; Walker (1989), p. 361; NADAL (1988), pp. 225-226; Farrén (1988), pp. 21 y ss.; García (1983), p. 161; Alfaro (1995), pp. 12-14; Vivanco (1994), pp. 57-59. La propuesta de FARIÑA (2014) de reconocer la figura del despido constructivo, que en apariencia es un autodespido, pero en realidad es un despido tácito, reduce el número de casos de autodespido, mas deja intacta la categoría conceptual.

${ }^{30}$ En este lugar no estamos abogando por una interpretación originalista de la ley, sino tratando de explicar por qué el artículo 171 omite una regla como la del artículo 168, inciso final. El valor que deba atribuírsele a esta explicación a la hora de interpretar la ley es otro asunto.
} 
el autodespido ${ }^{31}$. No obstante, tampoco la constatación de semejanzas entre el despido y el autodespido puede llevar a concluir necesariamente que las dos figuras son iguales en todo ${ }^{32}$.

Las diferencias legales entre el despido y el autodespido existen desde que este es reconocido por la ley de manera expresa (1966), dando cuenta así de diferencias fácticas consideradas jurídicamente relevantes ${ }^{33}$. Desde la perspectiva del cómputo del plazo, la diferencia que hace la ley resultaría de una circunstancia crucial: el hecho de si es el empleador o el trabajador quien por su declaración resuelve el contrato ${ }^{34}$. Simplificando las cosas, podría decirse

${ }^{31}$ Otras semejanzas han sido extraídas por la jurisprudencia; por ejemplo, la posibilidad de anular el despido indirecto cuando hay cotizaciones impagas (por todas, Corte Suprema, rol № 27871-2017, de 27 de septiembre de 2017) o la de utilizar la tutela laboral en el caso del autodespido (por todas, Corte Suprema, rol No 18465-2016, de 5 de septiembre de 2016). Nos reservamos el disentir de esta jurisprudencia, porque podría responder al mismo patrón que estamos criticando aquí. Así y todo, habría una diferencia entre el caso de la nulidad y la tutela, que nos llevarían a admitir la segunda y rechazar la primera, por las razones que apunta SiERRA (2010), pp. 327-331 y nota 6.

32 Este es el error en que incurre, por ejemplo, Corte de Apelaciones de Santiago, rol № 435-2016, de 22 de abril de 2016, cons. $5^{\circ}$, cuando concluye que la regla de suspensión del plazo se aplica por igual al trabajador despedido y al que se autodespide, porque "el legislador hace aplicable el mismo régimen jurídico en cuanto a reclamar el derecho a ser indemnizado".

33 En efecto, la ley consagra varias. Entre estas cabe anotar: en el caso del despido injustificado y carente de fundamento plausible, la indemnización es debida por el empleador, mientras que en el autodespido la indemnización es debida por el trabajador; en el caso del despido, el plazo de 60 días se cuenta desde la separación, mientras que en el autodespido, desde la terminación del contrato; la obligación de las comunicaciones y avisos del artículo 160 recae sobre el trabajador en el caso del despido indirecto; en el despido indirecto, si no se prueban las causales de caducidad, se entiende que la relación termina por renuncia, mientras que en el despido patronal por desahucio.

${ }^{34}$ En general, la doctrina señala la voluntad del trabajador como uno de los elementos característicos del autodespido, ThaYer y Novoa (2009), p. 115; Barahona (2010), pp. 9-10; Vivanco (1994), p. 130; Benavides (2009), p. 128. Por supuesto, nadie omite que la causa de la decisión del trabajador es el incumplimiento de las obligaciones del empleador. Pero hay doctrina, UGARTE (2009), p. 94; CAAMAÑo, (2016), y con ella jurisprudencia, que traslada el peso de la decisión del autodespido al empleador, hasta el punto de eliminar las diferencias y afirmar que corresponde "a un acto unilateral del empleador" (ver nota 41). Entendemos que una posición como esta venga alimentada por la experiencia de tantos casos en que el empleador crea las circunstancias para inducir en el trabajador la decisión de renunciar y eximirse del pago de las indemnizaciones. Sin embargo, negarle a la voluntad del trabajador el efecto esencial de poner término al contrato y crear así un supuesto diferente al despido patronal, es un exceso que se acerca al paternalismo, porque reduce la decisión de un individuo libre a una respuesta refleja carente de intencionalidad y estimulada por la sola voluntad del empleador. Es el problema que vemos en la sentencia de la Corte de Apelaciones de Concepción, rol № 152-2009, de 16 de diciembre de 2009, cons. $2^{\circ}$, cuando afirma que el autodespido es el anverso del despido tácito, "motivo por el cual [en el autodespido] no se puede atribuir el fin de la relación laboral a la voluntad del trabajador". En este punto, la propuesta de FARIÑA (2014) es valiosa, al salvaguardar el valor de la voluntad del trabajador que se autodespide, introduciendo una figura de despido tácito (el despido constructivo) que recoge aquellas situaciones en que realmente la voluntad del trabajador estaría viciada por fuerza o dolo del empleador. 
que en el despido indirecto el trabajador conoce la fecha de término del contrato con antelación. De ello se sigue que, sin perjuicio de las causas ajenas a su voluntad que lo impulsan al autodespido, puede programar su salida y, consecuentemente, defender sus intereses con cierta ventaja respecto de quien desconoce la fecha de término de contrato hasta el momento mismo en que es despedido ${ }^{35}$. Esta suerte de ventaja del trabajador que se autodespide respecto del trabajador que es despedido es compensada con la regla que suspende el plazo. Este fue el razonamiento de la Corte Suprema en 2007:

"la mayor laxitud para la contabilización del lapso de que se trata, aparece lógica dentro del contexto general del cuerpo normativo del ramo, cuando la decisión de poner término al vínculo laboral ha sido del empleador, pues ella posibilita al trabajador efectuar todas las gestiones necesarias ante la autoridad administrativa a fin de que le sean solucionadas la prestaciones que estime procedentes, antes de tener que accionar judicialmente, tanto por la factibilidad que su pretensión sea satisfecha en esa sede, sin las consecuencias que implica un juicio, como por la mayor claridad o certeza que los descargos de la reclamada puedan significar en relación a los planteamientos de su libelo"36.

\section{4. ¿Interpretación de la ley o integración del derecho?}

En la aplicación judicial del derecho es relevante la distinción entre interpretación de la ley e integración del derecho ${ }^{37}$. A grandes rasgos, la primera tarea corresponde a la actividad de determinar el sentido y alcance de una re-

\footnotetext{
35 VIVANCO (1994), p. 130: "Solamente si el trabajador está en situación inequívoca de probar los hechos que le atribuye el patrón como constitutivos de la causal [de autodespido] y tiene la certeza absoluta de que tales hechos configuran la causal invocada, debe iniciar la acción respectiva (...). El trabajador, una vez que haya meditado con tranquilidad su decisión y previo asesoramiento legal, debe ponerle término al contrato". Reconocemos la ingenuidad del tono que utiliza el autor; solo nos interesa ilustrar la sensibilidad existente en la época del debate legislativo.

${ }^{36}$ Corte Suprema, rol № 350-2007, de 28 de noviembre de 2007, cons. $7^{\circ}$. Mella (2001), p. 99, ofrece una explicación distinta, harto discutible: "la omisión [del artículo 171] resulta explicable porque carece de objeto un eventual reclamo [ante la Inspección del Trabajo] fundado en que el empleador incurrió en una causal de término de la relación laboral, toda vez que sólo el juez puede ordenar el pago de indemnizaciones si se establece la efectividad de la infracción contractual por culpa del empleador".

${ }^{37}$ ATRIA (2016), pp. 219-229, explica esta relevancia desde una perspectiva institucional, donde la jurisdicción que integra/crea derecho se transformaría en algo distinto: administración o legislación, según el caso. Esta diferencia, sin embargo, es prácticamente irrelevante en el marco conceptual del interpretativismo de DWORKIN. En efecto, allí las diferencias entre comprender, interpretar y crear derecho son irrelevantes, porque el derecho se construye creativamente mediante la interpretación, que está orientada a conservar y fortalecer la integridad del ordenamiento jurídico a partir de los principios. La posición de Gamonal (2009), ver notas 58 y 61, y UGARTE (2014), ver sección 5, parece inscribirse en este marco teórico. Para una crítica reciente a estos postulados - que suscribimos-, RosLer (2018).
} 
gla del ordenamiento jurídico, mientras que la segunda a la de crear una regla que complete el ordenamiento jurídico. En esta sección se intenta mostrar que la suspensión del plazo en el despido indirecto no puede ser calificada como el resultado de una labor hermenéutica, sino como una forma de integrar el derecho, porque se crea una regla nueva.

La Corte Suprema entiende que la aplicación de la regla del artículo 168, inciso final, al supuesto del autodespido es resultado de una actividad interpretativa. La fórmula utilizada por los jueces en estos casos y que se ha vuelto típica es:

"la interpretación armónica de los artículos 168 y 171 del Código del Trabajo permite concluir que en el caso del 'autodespido' el plazo para reclamar en sede judicial se suspende en el evento que se efectúe un reclamo ante la Inspección del Trabajo, dado que no existe razón de ninguna índole que permita sostener un diferente tratamiento jurídico para el despido y el 'autodespido', en lo concerniente a la forma cómo se deben computar los plazos para impetrar las acciones pertinentes..." ${ }^{\prime \prime 8}$.

A dicha fórmula la acompaña ordinariamente la siguiente: el denominado "Principio Protector", que informa el derecho laboral, y que "en materia de interpretación de enunciados normativos se manifiesta en el 'In dubio pro operario', [implica que] los jueces en caso de duda debieron recurrir en elección de la exégesis más favorable al trabajador" ${ }^{\prime \prime 39}$.

Los dos argumentos anteriores se fundan sobre la premisa de que el trabajador que es despedido y el trabajador que se autodespide son casos iguales entre sí. La formulación más clara de esta idea se encuentra en la sentencia de unificación de jurisprudencia ya referida: "el criterio de este tribunal ha sido el de asemejar el auto despido o despido indirecto en todo orden de materias al despido, como acto unilateral del empleador" ${ }^{\prime 40}$. Como tendremos ocasión de advertir más adelante, aquí los jueces están sustituyendo al legislador en la valoración de los supuestos fácticos que tuvo en cuenta al dictar la regla ${ }^{41}$.

Si se examina con cuidado la operación por la cual los jueces llegan a la conclusión de aplicar la regla de suspensión de la caducidad del plazo del artículo 168 al artículo 171, se advierte que ella no corresponde a un ejercicio de interpretación de la ley. Este es el análisis que haremos a continuación.

\footnotetext{
38 Por todas, Corte Suprema, rol № 41024-2016, de 24 de agosto de 2016, cons. $10^{\circ}$.

39 Por todas, Corte Suprema, rol № 41024-2016, de 24 de agosto de 2016, cons. $10^{\circ}$.

${ }^{40}$ Corte Suprema, rol № 5780-2015, de 21 de enero de 2016, cons. $9^{\circ}$. Ver nota 13.

${ }^{41}$ Ver nota 57.
} 


\subsection{La incorreción del argumento de la "interpretación armónica"}

El intérprete debe partir de la base de que el conjunto de las disposiciones legislativas es coherente $y$, sobre esta premisa -que orienta su labor-, preferir la interpretación que permita la coexistencia armónica de las normas. Este criterio interpretativo, sin embargo, no deja en manos del intérprete definir arbitrariamente el canon armónico de las leyes. La misma base sobre la que se asienta el principio de la interpretación armónica -esto es, que el legislador es un agente razonable que evita dictar normas contradictorias entre sí- sirve de asiento a la hora determinar cuál es esa armonía ${ }^{42}$. En otras palabras, la interpretación armónica consiste en que las normas guarden entre sí la armonía que el legislador quiso darles, y no las que el intérprete cree que deberían tener ${ }^{43}$.

Cuando la Corte Suprema invoca el principio de la interpretación armónica entre el artículo 168, inciso final, y el artículo 171, para aplicarle al despido indirecto la regla de suspensión del plazo de caducidad de la acción, ¿está interpretando la ley de acuerdo a la armonía que el legislador quiso que tuvieran? Para responder a esta pregunta, el intérprete debe establecer lo que el legislador quiso decir y los motivos que tuvo para querer decir eso, y no lo que a su juicio debió decirr4 ${ }^{44}$ En este caso, no hay esfuerzo alguno por parte de los jueces en identificar cuál podría haber sido la razón tenida en cuenta por el legislador para negar al despido indirecto una regla que le reconoce al despido patronal. En cambio, elude el problema definiendo que el supuesto del despido y del autodespido son en todo iguales $u$ homologables y que, por lo tanto, una interpretación armónica exige extender la regla del inciso final

${ }^{42}$ GuZMán (2011), p. 148.

${ }^{43}$ GuZmán (2011), p. 148: se trata de reconocer la debida armonía "y no (...) una correspondencia y armonía a toda costa, incluso forzando significados". Entendemos que esta conclusión sea válida únicamente para quienes comparten la premisa de que el texto a interpretar impone restricciones al intérprete no sólo desde su estructuración literaria sino también desde su espíritu, esto es, desde la intención con que fue redactada. Para quienes, por el contrario, parten de la premisa de que la interpretación judicial es un proceso constructivo y creativo, no restringido sino orientado por el texto normativo y su espíritu, esta conclusión con razón les dejará indiferentes. Pero en este caso deberán admitir con nosotros que, entonces, carece de sentido atribuirle al criterio de la interpretación armónica un carácter de principio que el juez debe observar, como sugiere la Corte Suprema.

${ }^{44}$ EKINS (2012) identifica dos elementos esenciales de la actividad interpretativa fiel a la intención del legislador: el significado intencionado (intended meaning) y la elección razonada (reasoned choice). El primero consiste en "la formulación que el legislador hace de las proposiciones legales que elige introducir", EKINS (2012), p. 211, y el segundo en "la cadena de medios y fines que explica la regla", EkINs (2012), p. 279. Este segundo elemento, que se identifica con el "espíritu" de la ley, EkINs (2012), p. 275, podría corresponderse con lo que en Andrés Bello es "la razón suficiente de una disposición (esto es, la razón o conjunto de razones que la han dictado)" [GuZmán (2011), p. 96]. 
del artículo 168 al autodespido ${ }^{45}$. Tampoco se esfuerza por demostrar que este habría sido el supuesto que el legislador tuvo presente; simplemente ignora la cuestión partiendo precisamente de aquello que debía ser demostrado.

\subsection{Los problemas de la interpretación in dubio pro operario}

En el contexto de su aplicación judicial, el principio in dubio pro operario es útil para orientar la tarea del intérprete cuando se encuentra frente a una alternativa de dos o más respuestas legales al caso que debe resolver ${ }^{46}$. Siendo todas esas respuestas válidas como solución al caso, el intérprete optará por aquella que resulte más favorable al trabajador.

Sin embargo, el principio in dubio pro operario es insuficiente para orientar al intérprete en la tarea de identificar cuál o cuáles son las respuestas que la ley ofrece al conflicto jurídico. El principio se vuelve operativo sólo una vez que el intérprete ha identificado dos o más respuestas legales posibles al problema, lo que resulta de contrastar los hechos con las descripciones normativas ${ }^{47}$. Así, mediante sucesivos intentos, se van incorporando y descartando posibilidades hasta que se llega, en el mejor de los casos, a una respuesta única o a un conjunto reducido de posibilidades.

En la cuestión de si aplicar la regla del inciso final del artículo 168 al artículo 171, el principio in dubio pro operario es útil para el intérprete sólo cuando ya se ha establecido que la aplicación de la regla en el caso del autodespido es

45 Un buen ejemplo se encuentra en el cons. $6^{\circ}$ de Corte de Apelaciones de Santiago, rol № 435 2016, de 24 de abril de 2016: "Conforme [a la regla del artículo 22, inciso primero, del Código Civil], la disposición del inciso primero del artículo 171 del Código del Trabajo debe armonizarse con lo que dispone el artículo 168 del mismo Código en su último inciso, de tal manera que el ejercicio de los derechos laborales -independientemente de quien ponga término al contrato- quede sometido a iguales normas, incluidos los plazos para reclamar la tutela respectiva".

${ }^{46}$ Este principio es útil también para la tarea del legislador que enfrenta múltiples opciones en la búsqueda de la solución legislativa más acorde a las necesidades del trabajador, PLA (2015), p. 40. En este punto, Gamonal (2009), p. 103, es de la opinión contraria, al estimar que el principio cumple una función de orientación moral y deja al legislador libre de reemplazarlo por otro. También incide en el proceso laboral, como ilustra por ejemplo SıIvA (2015), pp. 61-62, a propósito de la compatibilidad de la acción de tutela y la de autodespido. En esta línea, sin embargo, advierte PaLomo (2015), p. 395, cómo bajo su auspicio se pueden llegar a vaciar de contenido "pilares esenciales de la idea misma de proceso, debilitándolo como instrumento idóneo para resolver los conflictos con sentencias de calidad". Una referencia amplia a los principios jurídicos laborales en Chile en López (2013), pp. 33-106.

47 Sobre esta premisa, los alcances del principio in dubio pro operario son debatidos en la doctrina. Por una parte, autores como Gamonal (2013) y UGarte (2014) le atribuyen al principio una función integradora del derecho que permitiría al juez crear una norma para el caso particular, mientras que otro sector restringe ese alcance al espíritu de la ley, THAYER y NOVOA (1998), pp. 27-29, negándole el uso para integrar vacíos legales o la creación de situaciones no previstas por la ley [MUNITA (2014), pp. 27-29]. Esta última es también la posición de PLA (2015), p. 94. 
una respuesta posible al problema, porque recién entonces el intérprete puede legítimamente preguntarse qué debe hacer: si aplicar la suspensión del plazo de la acción de despido injustificado al autodespido o no aplicarla.

Postular que el principio in dubio pro operario debe conducir al intérprete a aplicar la regla de la suspensión del plazo al despido indirecto, supone que antes se demostró que la aplicación de esa regla a ese caso es el resultado de una labor hermenéutica ${ }^{48}$. Afirmar simplemente que la regla del artículo 168, inciso final, es aplicable al artículo 171, para luego aplicarla en virtud del principio in dubio pro operario, implica eludir el deber esencial del intérprete, que es justificar por qué es aplicable ${ }^{49}$.

\subsection{La improcedencia de una interpretación correctiva de la ley por extensión}

¿No podría ser este precisamente un caso en que el juez, exigido por la equidad, corrige la ley interpretando extensivamente la regla del artículo 168, inciso final ${ }^{50}$ ? Antes de desarrollar la respuesta, conviene recordar que esta clase de interpretación es de carácter excepcional y, por lo tanto, debe aplicarse restrictivamente ${ }^{51}$. Ahora, para que se dé esta interpretación es necesario, en primer lugar, que la situación a la que se extiende la aplicación de la regla haya sido involuntariamente omitida por el legislador y, en segundo lugar, que las razones que el legislador tuvo presentes para establecer la regla en un caso sigan siendo válidas en el caso hacia el que se extiende su aplicación ${ }^{52}$.

A juicio nuestro, en este caso no se cumple ninguna de las dos condiciones. La primera, porque hay buenas razones para sostener que la omisión del artículo 171 no fue involuntaria, a menos que alguien quiera entender como una

\footnotetext{
48 Para Gamonal (2009), pp. 106-107, este movimiento en dos fases carecería de sentido, porque no hay un "antes" a la aplicación del principio: la duda del intérprete frente a la norma es intrínseca a su labor; en todo caso, la aplicación del principio estaría restringida a los casos difíciles o dudosos.

49 PlA (2015), pp. 55-56, señala los riesgos asociados al uso de los principios en la interpretación judicial y, en pp. 86-87, advierte que el principio protector (que incluye el in dubio pro operario) no debe usarse para resolver los conflictos jurídicos: "el intérprete debe utilizar el mismo criterio que el legislador, mientras no lo reemplace ni lo supla, manteniendo el mandato y espíritu de la ley". GAMONAL (2009), pp. 106-107, discrepa en este punto. Para él, el supuesto carácter excepcional de la aplicación del principio (i. e., solo cuando hay dudas) no es tal, pues "aplicar el derecho es interpretarlo". En otras palabras, hasta las normas más simples son dudosas y requieren interpretación. Quedaría por explicar entonces por qué reservar la aplicación inmediata del principio in dubio pro operario solo a los casos difíciles o dudosos (ver nota 49).

${ }^{50}$ Esta posibilidad ya está claramente reconocida en ArISTÓteles, Nic. Eth. 5.10.3 y ss.

51 EKINS (2012), p. 276.

52 Aristóteles, Nic. Eth. 5.10.5. Lo mismo Andrés Bello en nuestra tradición, Guzmán (2011), p. 111.
} 
imprevisión del legislador todo lo que éste pudo decir y no dijo ${ }^{53}$. Tampoco se cumpliría la segunda condición porque, como hemos visto más arriba, hay argumentos para sostener que el legislador quiso distinguir entre el despido patronal y el despido indirecto para efecto del cómputo del plazo de caducidad. Luego, no podría afirmarse pacíficamente que las razones para suspender el plazo en el caso del artículo 168 son también válidas para el caso del artículo 171.

En definitiva, no sería este un caso en que el texto de la ley expresa inadecuadamente la intención del legislador ${ }^{54}$. Por lo mismo, sería improcedente una extensión de su alcance en nombre de la equidad.

\subsection{La improcedencia de la analogia legis}

De las sentencias que extienden la aplicación de la regla del artículo 168, inciso final, se infiere que está operando el axioma "donde existe la misma razón, debe existir la misma disposición". La Corte afirma que no existe motivo alguno que justifique un trato distinto entre el autodespido y el despido en materia de cómputo del plazo para recurrir a tribunales. Sería un caso de analogia legis, en que una regla del supuesto del despido patronal (suspensión del plazo) se aplica a un supuesto análogo -el despido indirecto- que carece de ella. La Corte Suprema estaría entonces Ilenando un vacío legal, una laguna legislativa: el legislador habría omitido establecer una regla allí donde debía existir, y los jueces subsanan esa omisión por vía de la integración analógica.

La estructura de este modo de conocer consiste en inferir una relación desconocida a partir de la semejanza que uno de sus elementos tiene con el de otra relación conocida ${ }^{55}$. En este caso sería: si el cómputo del plazo se suspende para el despido, y el autodespido es semejante al despido, entonces el plazo debe suspenderse para el autodespido. Pero la integración analógica acarrea una objeción intrínseca: no es interpretación de la ley, sino creación del derecho ${ }^{56}$.

\footnotetext{
${ }^{53}$ Ver arriba sección 3.1.

${ }^{54}$ Como explica Ekıns (2012), p. 281, en estos casos "el significado intencionado (intended meaning) de la disposición legal es más restringido que la decisión razonada (reasoned choice) por los legisladores", es decir, el texto dice menos de lo que los legisladores quisieron que dijera.

55 Perelman (1979), p. 129.

${ }^{56}$ La analogía es uno de los medios de integración judicial del derecho, Lizama y UGarTe, (1998), p. 100, y descansa en los principios, que tienen entre sus funciones la de integrar el derecho, esto es, "la de construir una norma para resolver el caso concreto", GamONAL (2013), p. 448. EkIns (2012), p. 279, considera que la interpretación por analogía no es lícita, "porque se separa de lo que el legislador ha elegido [...]; no es deferente con el ejercicio de la autoridad del legislador". En este mismo sentido, la Corte Suprema, rol № 350-2007, de 28 de noviembre de 2007, cons. $8^{\circ}$, afirmó que respecto de la regla de suspensión de caducidad del plazo no se vislumbraba "pretexto alguno para hacer una interpretación analógica que, en la especie, sólo distorsiona la expresa voluntad del legislador".
} 
La comparación analógica entre el despido patronal y el autodespido presupone haber establecido un punto de semejanza entre ellos que gatilla como conclusión que la regla de suspensión del plazo debe extenderse desde un caso al otro. Pero la determinación de esta igualdad jurídica entre ambos supuestos implica una ponderación de la significación jurídica de las diferencias y semejanzas fácticas que hay entre ellos. Este proceso de determinación no es lógico, sino axiológico ${ }^{57}$. En este caso, cabe concluir que la evaluación por la que los jueces Ilegan a concluir la semejanza entre el despido y el autodespido es distinta a la que hizo el legislador cuando decidió que la suspensión solo corría para el despido patronal. Por consiguiente, la extensión de la regla del artículo 168, inciso final, por vía de analogía no sería una forma de interpretar el derecho legislado, sino de corregirlo ${ }^{58}$.

\section{La problemática creación judicial de una regla praeter legem}

De la sección anterior debería concluirse que la extensión de la regla de suspensión de caducidad del plazo no es resultado de una actividad hermenéutica, sino correctora del Derecho: los jueces dicen que advierten un vacío legal y lo corrigen dictando una regla ${ }^{59}$. El criterio de identificación propio de esta forma de integrar el Derecho praeter legem es axiológico ${ }^{60}$, y coherente con la función que un sector de la doctrina le atribuye el derecho del trabajo ${ }^{61}$. Luego, es razonable preguntarse si la jurisprudencia que hemos estado analizando críticamente no es más bien el resultado normal de las premisas de la disciplina, inmune por tanto a las objeciones ofrecidas por quienes no las comparten.

En un ensayo publicado en 2014, Ugarte defiende un concepto de derecho del trabajo que es independiente de la ley: hay reglas legales laborales que no pueden considerarse parte del derecho del trabajo ${ }^{62}$. Para negarles validez a estas normas legales positivas - que no son derecho del trabajo- es preciso "superar el incómodo corsé positivista" mediante la rehabilitación de los principios de

\footnotetext{
57 Perelman (1979), pp. 129-130. Lizama y Ugarte (1998), p. 134: la aplicación legítima de la analogía descansa en una semejanza axiológica entre los términos analogados, no reducibles a la lógica, por tanto.

${ }^{58}$ Gamonal (2009), pp. 108-109, postula abiertamente que el juez "debe crear una regla específica para el caso concreto" si enfrenta una laguna normativa o axiológica. Axiológica es la laguna que resulta cuando el legislador omite una propiedad relevante a la luz de los principios jurídicos del sistema.

${ }^{59}$ Esta sería la forma en que se hace presente el riesgo de la constitucionalización del derecho [CORRAL (2014), pp. 11-14].

${ }^{60}$ Perelman (1979), p. 48.

${ }^{61}$ Gamonal (2009), pp. 106-109.

62 Ugarte (2014), p. 7.
} 
la disciplina ${ }^{63}$. Pero una rehabilitación que le haga justicia a la naturaleza de esos principios requiere un marco conceptual distinto del positivismo, y que no es tampoco el iusnaturalismo ${ }^{64}$. Este nuevo marco conceptual se encuentra en "las potentes corrientes que construyen su concepción del derecho desde la constatación de los principios como un elemento central del sistema jurídico" ${ }^{65}$. La centralidad de los principios consiste en su eficacia normativa inmediata: son derecho directamente aplicable por el juez.

Apoyándose en la supremacía de la Constitución, Ugarte les reconoce a los principios una función rectora en el sistema jurídico: identificados con los derechos fundamentales constitucionales, "la validez y la aplicación de las reglas de inferior rango -legales y contractuales- [deben] someterse a aquéllos" ${ }^{\prime 66}$. Esta función de corrección del derecho la cumplen los principios apelando al ideal moral que sustenta el derecho del trabajo desde su núcleo: la protección del trabajador.

Los principios del derecho del trabajo servirán al juez para resolver los casos difíciles; es decir, aquellos en que hay norma, pero "no hay acuerdo sobre sobre su significado (problemas de interpretación), o [aquellos en que] no existe ninguna norma aplicable al caso (problema de laguna) ${ }^{\prime \prime 67}$. Al mismo tiempo, los principios servirán para juzgar las decisiones del juez: su desajuste con el ideal moral del derecho del trabajo hace que ellas sean "políticamente injustas, ya que no protegen al trabajador como contratante débil" y jurídicamente incorrectas, "en cuanto desconocen la dimensión ideal del derecho"68.

En una concepción del derecho del trabajo como la de Ugarte, es innecesario disimular que el juez se aparta de la legalidad para proteger al trabajador. Las razones para que un tribunal se atenga al texto de la ley (concediéndole todo el margen de interpretación que admitan las palabras) son excusadas por la defensa del ideal moral del derecho del trabajo. La aplicación directa de los

${ }^{63}$ UGarte (2014), p. 9. En la nota al pie n. 5 define lo que entiende por positivismo.

${ }^{64}$ UGARTE (2014), p. 17.

${ }^{65}$ UgarTe (2014), p. 18. Más adelante caracterizará esta concepción como un "no positivismo de origen principalista", p. 19. Es difícil ignorar la similitud con la teoría de DwORkIN, que se presenta como una opción entre el convencionalismo (positivismo) y el pragmatismo (iusnaturalismo), basada en los principios jurídicos: DwOrkin (1986), capítulo 7.

66 UGARTE (2014), p. 18.

${ }^{67}$ UGARTE (2014), p. 26.

${ }^{68}$ UGARTE (2014), p. 28. Así también operan los principios para juzgar las decisiones legislativas. Aunque se reconoce al legislador libertad para dictar reglas que puedan afectar al trabajador, su validez está condicionada por el ideal moral del derecho del trabajo, que se ponderará en cada caso según el principio de proporcionalidad: UGARTE (2014), pp. 24-25. 
principios para resolver los casos difíciles coloca a los jueces no por sobre los legisladores, sino en el lugar de los legisladores ${ }^{69}$.

A diferencia del legislador, los jueces pueden pensar que la diferencia anotada entre el despido patronal y el despido indirecto no es suficientemente relevante como para justificar una regla que favorezca al trabajador despedido y no al que se autodespidió. De hecho, es lo que piensan algunos de nuestros magistrados. Esta diferencia de criterio, en el marco de una concepción como la de Ugarte, debe entenderse como una autorización para que los jueces corrijan la voluntad del legislador, expresada en la asignación de una regla a un supuesto y no a otro.

Sin embargo, las premisas sobre las cuales se defiende la creación judicial de normas jurídicas son problemáticas. Uno de los puntos controvertidos es la coexistencia de lo jurídico y lo político como ámbitos de decisión diferenciados, aunque intersecten entre sí. Esta diferenciación, con toda la complejidad de su proyección institucional, es puesta en entredicho cuando se admite que el juez pueda colmar las lagunas axiológicas creando una regla como si fuera el legislador ${ }^{70}$.

No debe perderse de vista que la decisión del legislador de beneficiar al trabajador despedido con una regla que no aplica, en cambio, para el trabajador que se autodespide, está precedida por una valoración del significado de ser despedido y de autodespedirse. Es indiscutible que estos supuestos admiten una gama de valoraciones diferentes, las que a su vez se proyectarían de manera diferente en la ley. La tarea del legislador es ponderar las diferentes posibilidades y decidir. La deliberación parlamentaria consiste precisamente en esto. Este ámbito de deliberación es político ${ }^{71}$.

Es perfectamente razonable que haya desacuerdo con el juicio del legislador expresado en la ley. Donde ellos estimaron que las diferencias entre el despido patronal y el despido indirecto justificaban beneficiar al primero con una regla que niegan al segundo, alguien podría estimar que las semejanzas entre

\footnotetext{
${ }^{69}$ De hecho, en la teoría de Dworkin los jueces son colegisladores porque no existiría una separación entre política y derecho. DWORKIN (1986), pp. 223 y 183-186.

${ }^{70}$ Desde aquí se dirige la crítica de AtrIA (2016) a quienes minusvaloran la forma del derecho y las consecuencias que tiene para la función jurisdiccional. Ver nota 37.

${ }^{71}$ La autonomía relativa de lo político respecto de lo jurídico/judicial es una premisa de este trabajo. Por ella entendemos esa condición esencial de la organización social que consiste en fijar criterios para distinguir entre un "ellos" y un "nosotros", que no contraría una exigencia moral, sino que la posibilita. Esta autonomía de lo político encuentra una específica expresión en la noción escolástica de determinatio, Tomás DE Aquino, Summa theologiae, I-II, q. 95: el legislador prudencialmente determina las exigencias de la justicia entre un conjunto amplio de soluciones posibles. Esta autonomía responde también a razones de equidad en una sociedad democrática: Quod omnes tangit ab omnibus decidentur.
} 
ambos ameritan sobradamente disponer la misma regla en cualquier caso. Para aquellas situaciones en que estas divergencias son extremas y se estima que el legislador en su juicio desconoció las garantías básicas de las personas, existen varios mecanismos específicos que pueden, en general, agruparse en una misma función: el control de constitucionalidad de la ley. Pero fuera de estos casos, que en principio serán extraordinarios, se le reconoce al legislador un ámbito de libre discrecionalidad, propio de la actividad política ${ }^{72}$.

Cada vez que los jueces -fuera de los procedimientos de control de constitucionalidad-corrigen la valoración política que subyace a las reglas legales, realizan ellos una actividad que podría calificarse como política. Al sustituir el criterio del legislador por un criterio distinto, según el cual las semejanzas entre el despido y el autodespido son suficientemente relevantes como para justificar la aplicación de la misma regla en ambos casos, los jueces estarían actuando como políticos y la política se estaría judicializando.

\section{Conclusión}

La extensión de la regla de suspensión de caducidad del plazo desde el despido patronal (artículo 168) al despido indirecto (artículo 171) es una jurisprudencia que debería entenderse en un contexto más amplio que el del derecho del trabajo. Si a la luz de los principios laborales la respuesta de los tribunales al trabajador autodespedido podría ser plenamente justificada, al ponderarse desde los fundamentos de la organización de los poderes estatales ya no lo es tanto. En efecto, la jurisprudencia sobre el inciso final del artículo $168 \mathrm{CdT}$ puede entenderse como una transgresión de la frontera entre el Poder Judicial y el Poder Legislativo; en otras palabras, como una manifestación del fenómeno de la judicialización de la política.

La judicialización de la política es un fenómeno que debería ser juzgado críticamente por quienes entienden que, en la base de las diferencias institucionales que caracterizan al Poder Judicial y al Poder Legislativo, descansa la distinción entre lo jurídico y lo político. Y es que la separación que deben guardar entre sí jueces y legisladores obedece, finalmente, a garantizar una adecuada correspondencia entre la naturaleza de los fines - políticos y jurídicos- y los medios para alcanzarlos. El respeto que los jueces deben observar con el

\footnotetext{
72 Dos sentencias recientes que reconocen la autonomía del legislador para definir lo justo legal son Corte Suprema, rol No 40179-2017, de 6 de noviembre de 2017, cons. $4^{\circ}$, en que condiciona el ejercicio del derecho a voto de la población privada de libertad a la forma como lo determine el legislador, y Tribunal Constitucional, rol No 3729-17, 28 de agosto de 2017, cons. 26º , en donde afirma que es al legislador "a quien corresponde apreciar la manera en que se busca solucionar un determinado problema en la sociedad", en este caso para despenalizar el aborto.
} 
derecho legislado es una de las manifestaciones de la separación que media entre jueces y legisladores, que proyecta esa otra distinción entre los ámbitos de lo jurídico y de lo político.

La crítica a la jurisprudencia sobre el plazo de caducidad de la acción de indemnización en el despido indirecto podría entenderse, en último término, como una defensa de lo político, y en particular de las legítimas competencias del Poder Legislativo, frente a la amenaza de una concepción jurídica totalizadora de la vida en común.

\section{Bibliografía CITADA}

Alfaro, Jorge (1995): El autodespido en la legislación laboral chilena (memoria de prueba inédita) (Valparaíso, Pontificia Universidad Católica de Valparaíso).

ArIstóteles, Nicomachean Ethics (Traducc. Harris Rackham, Cambridge, Harvard University Press).

ATRIA, Fernando (2016): La forma del Derecho (Madrid, Marcial Pons).

Barahona, Francisca (2010): Despido indirecto (Santiago, Thomson Reuters/ PuntoLex).

Benavides, Carlos (2009): El despido en la nueva justicia laboral (Santiago, Thomson Reuters/PuntoLex).

CAAmaño, Eduardo (2016): "Despido indirecto", en: Revista de Derecho Laboral y Seguridad Social (Vol. IV № 2).

Congreso Nacional (1996): "Historia de la Ley No 19.447", en BCN. Disponible en www.bcn.cl/historiadelaley [fecha de consulta: 4 de enero de 2018].

CORRAL, Hernán (2014): "Constitucionalización del derecho civil. Reflexiones desde el sistema jurídico chileno", en: Villabella, Carlos; Pérez, Leonardo, y Molina, Germán (coords.), Derecho civil constitucional (México, Grupo Editorial Mariel S.C.), pp. 1-16.

Dighero, Andrés (2016): "Despido indirecto", en: Revista de Derecho Laboral y Seguridad Social (Vol. IV No 3).

DWORKIN, Ronald (1986): El imperio de la justicia, $3^{a}$ reimpresión, 2008 (Traducc. Claudia Ferrari, Barcelona, Gedisa).

EkINS, Richard (2012): The nature of legislative intent (Oxford, Oxford University Press).

FARIÑA, Lautaro (2014), "Despido tácito y despido constructivo: Implicancias en la legitimación pasiva de la tutela de derechos fundamentales", en: Estudios Laborales de Sociedad Chilena del Derecho del Trabajo ( $\left.\mathrm{N}^{\circ} 10\right)$. 
FarréN, Raúl (1988): Terminación del contrato de trabajo (Santiago, Editorial Jurídica Ediar-ConoSur).

Gamonal, Sergio (1998): Introducción al derecho del trabajo (Santiago, Editorial Jurídica ConoSur).

(2009): Fundamentos de derecho laboral (Santiago, LegalPublishing).

(2013): "El principio de protección del trabajador en la Constitución chilena", en: Estudios Constitucionales (Vol. XI, No 1), pp. 425-458.

(2016): "Despido indirecto", en: Revista de Derecho Laboral y Seguridad Social (Vol. IV No 1).

García, Fernando (1983): El autodespido o despido indirecto (memoria de prueba inédita) (Valparaíso, Pontificia Universidad Católica de Valparaíso).

GuZmán, Alejandro (2011): Las reglas del Código Civil de Chile sobre interpretación de las leyes (Santiago, Abeledo Perrot).

INSPECCIÓN DEL TRABAJO (2011): "Despido indirecto: análisis y jurisprudencia", en: Boletín Oficial (Vol. XXV, № 273). Disponible en: www.dt.gob.cl/documentacion/1612/articles-99864_recurso_1.pdf [fecha de consulta: 4 de enero de 2018].

LIzAMA, Luis, y UGARTE, José Luis (1998): Interpretación y derechos fundamentales en la empresa (Santiago, Editorial Jurídica ConoSur).

López, Marcos (2013): El principio de protección a la fuente del empleo en Chile (Santiago, Thomson Reuters).

Mella, Patricio (2001): "El despido indirecto o resolución del contrato de trabajo por incumplimiento patronal", en: Revista de Derecho Universidad de Concepción (Vol. LXIX, № 210), pp. 95-102.

MUNITA, Enrique (2014): "El principio protector y la regla del in dubio pro operario como criterio de interpretación de la norma laboral", en: Revista Chilena de Derecho del Trabajo y de la Seguridad Social (Vol. V, № 10), pp. 85-94.

NADAL, Daniel (1988): El despido en el Código del Trabajo (Santiago, Ediar-ConoSur). (2004): El despido en el Código del Trabajo (Santiago, LexisNexis).

Palomo, Diego (2015): "Proceso laboral chileno y la tutela judicial efectiva: Sobre el difícil avance hacia un mejor modelo que no sacrifique postulados elementales del debido proceso", en: Palomo, Diego (direc.), Proceso y justicia laboral: lecturas a contracorrientes (Santiago, Ediciones Jurídicas de Santiago y Universidad de Talca), pp. 381-429.

Perelman, Charles (1979): Logique Juridique (París, Dalloz).

PlA, Américo (2015): Los principios del derecho del trabajo, $4^{a}$ edición (Montevideo, Fundación de Cultura Universitaria). 
Rosler, Andrés (2018): "Hermes o la continuación de Antígona por otros medios. Una crítica del interpretativismo", en: Revista Jurídica Universidad de San Andrés (No 6), pp. 1-26.

SierRA, Alfredo (2010): "Acción de tutela laboral y despido indirecto. Comentario a la sentencia Gómez Cattini con Camilo Ferrón Chile S.A.", en: Revista de Derecho Universidad Católica del Norte (Año 17, N ${ }^{\circ}$ 2), pp. 325-331.

Silva, Claudia (2015): "Compatibilidad entre el procedimiento de tutela de derechos fundamentales y el despido indirecto", en: Revista de Derecho (Valdivia) (Vol. XXVIII, N²), pp. 51-69.

THAYER, William, y NOVOA, Patricio (1989): Manual de derecho del trabajo, $2^{\text {a }}$ edición (Santiago, Editorial Jurídica de Chile), tomo II.

(2009): Manual de derecho del trabajo, $4^{a}$ edición (Santiago, Editorial Jurídica de Chile), tomo II.

Tomás de Aquino: Summa theologiae, Textum Leoninum Romae 1892 editum. Disponible en http://www.corpusthomisticum.org/sth2095.html [fecha de consulta: 4 de enero de 2018].

UgARTE, José Luis (2009): Tutela de derechos fundamentales del trabajador, $2^{\text {a }}$ edición (Santiago, LegalPublishing).

UgARTE, José Luis (2014): Derecho del trabajo: Invención, teoría y crítica (Santiago, Thomson Reuters/LegalPublishing).

Vergara, Mónica (2016): "Despido indirecto", en: Revista de Derecho Laboral y Seguridad Social (Vol. IV, No 3).

Vivanco, Manuel (1994): El despido laboral (Santiago, Editorial Jurídica de Chile). WALKER, Francisco (1989): Derecho del trabajo y relaciones del trabajo (Santiago, Ediar-ConoSur).

\section{NORMAS JURÍDICAS CITADAS}

D.F.L. $N^{0} 1$, fija texto refundido, coordinado y sistematizado del Código del Trabajo. Diario Oficial, 16 de enero de 2003.

Ley $\mathrm{N}^{\circ}$ 20.087, que sustituye el procedimiento laboral contemplado en el Libro V del Código del Trabajo. Diario Oficial, 3 de enero de 2006.

\section{JURISPRUDENCIA CITADA}

Pereira Salgado Vivian con Brimax Productos Quimicos Ltda. (2007): Corte Suprema 28 de noviembre de 2007 (recurso de casación en el fondo, incumplimiento grave de las obligaciones que impone el contrato) en: www. 
westlawchile.cl (cita online: CL/JUR/2681/2007) [fecha de consulta: 3 de noviembre de 2018].

Soto Soto, Marcelo contra Proalmar S.A. (2008): Corte Suprema 8 de abril de 2008 (recurso de casación en el fondo y procedimiento correspondiente) en: www.westlawchile.cl (cita online: CL/JUR/898/2008) [fecha de consulta: 3 de noviembre de 2018].

Cifuentes Pérez, Juan Heriberto contra Universidad La República (2009): Corte de Apelaciones de Concepción 16 de diciembre de 2009 (recurso de nulidad y procedimiento correspondiente) en: www.westlawchile.cl (cita online: CL/JUR/4992/2009) [fecha de consulta: 3 de noviembre de 2018].

Vásquez Ramos María Isabel con Ministros de la Corte de Apelaciones de San Miguel (2014): Corte Suprema 11 de marzo de 2014 (recurso de queja, tutela y de cobro de prestaciones e indemnizaciones laborales) en: www. westlawchile.cl (cita online: CL/JUR/403/2014) [fecha de consulta: 3 de noviembre de 2018].

Juan Serrano Sánchez con integrantes de la Corte de Apelaciones de Valparaíso (2014): Corte Suprema 12 de mayo de 2014 (recurso de queja y procedimiento de aplicación general) en: www.westlawchile.cl (cita online: CL/JUR/2277/2014) [fecha de consulta: 3 de noviembre de 2018].

Sebastián Miño Sepúlveda con Ministros de la Corte de Apelaciones de Talca (2014): Corte Suprema 22 de diciembre de 2014 (recurso de queja y acción de autodespido) en: www.westlawchile.cl (cita online: CL/JUR/9727/2014) [fecha de consulta: 3 de noviembre de 2018].

Fernando Moreno Vásquez con Ricardo Vargas Clavijo y otros (2015): Corte Suprema 29 de octubre de 2015 (recurso de queja y despido indirecto, nulidad del mismo, cobro de prestaciones e indemnización de perjuicios o general) en: www.westlawchile.cl (cita online: CL/JUR/6552/2015) [fecha de consulta: 3 de noviembre de 2018].

Leonardo Cancino Medina con Consorcio RTDC S.A. (2016): Corte Suprema 21 de enero de 2016, (unificación de jurisprudencia laboral y procedimiento monitorio) en: www.westlawchile.cl (cita online: CL/JUR/541/2016) [fecha de consulta: 3 de noviembre de 2018].

Nicolás Valenzuela Salinas con Proactiva Servicio Industriales S.A. (2016): Corte de Apelaciones de Santiago 22 de abril de 2016 (recurso de apelación y acción de despido indirecto) en: www.westlawchile.cl (cita online: CL/JUR/2699/2016) [fecha de consulta: 3 de noviembre de 2018].

Leonardo Inostroza Villa con Ministros de la Corte de Apelaciones de Santiago (2016): Corte Suprema 24 de agosto de 2016 (recurso de queja y despido 
indirecto, nulidad del despido, cobro de prestaciones e indemnizaciones legales) en: www.westlawchile.cl (cita online: CL/JUR/7135/2016) [fecha de consulta: 3 de noviembre de 2018].

Lilian Urrutia Urrutia con Supermercado Bigger S.P.A. (2016): Corte Suprema 5 de septiembre de 2016 (unificación de jurisprudencia laboral y procedimiento de tutela laboral) en: www.westlawchile.cl (cita online: CL/JUR/6164/2016) [fecha de consulta: 3 de noviembre de 2018].

Amalia Arancibia Ordenes con Ministros de la Corte de Apelaciones de Santiago (2016): Corte Suprema 17 de noviembre de 2016 (recurso de queja y procedimiento ordinario) en: www.westlawchile.cl (cita online: CL/JUR/7690/2016) [fecha de consulta: 3 de noviembre de 2018].

Carlos Campos Baeza con Ministros de la Corte de Apelaciones de Santiago (2016): Corte Suprema 22 de diciembre de 2016 (recurso de queja y autodespido y cobro de prestaciones laborales) en: www.westlawchile.cl (cita online: CL/JUR/8485/2016) [fecha de consulta: 3 de noviembre de 2018].

Bruno Obrali Campanini con Ministros de la Corte de Apelaciones de Santiago (2017): Corte Suprema 23 de agosto de 2017 (recurso de queja y autodespido) en: www.westlawchile.cl (cita online: CL/JUR/5897/2017) [fecha de consulta: 3 de noviembre de 2018].

Pamela Canales Salvo con Servicios Educacionales Limitada y otro (2017): Corte Suprema 27 de septiembre de 2017 (recurso de unificación de jurisprudencia laboral y demanda en procedimiento ejecutivo) en: www.westlawchile. Cl (cita online: CL/JUR/6261/2017) [fecha de consulta: 3 de noviembre de 2018].

Piña Riquelme (INDH) con Servicio Electoral y Gendarmería de Chile (2017): Corte Suprema, rol 40179-2017, de 6 de noviembre de 2017 (recurso de protección y derecho a voto de personas privadas de libertad) en: http:// bibliotecadigital.indh.cl/bitstream/handle/123456789/1102/CS\%20confirma $\% 20$ sentencia.pdf? sequence $=2$ [fecha de consulta: 3 de noviembre de 2018].

Requerimiento de inconstitucionalidad presentado por un grupo de senadores, que representan más de la cuarta parte de los miembros en ejercicio, respecto del proyecto de ley que regula la despenalización de la interrupción voluntaria del embarazo en tres causales (2017): Tribunal Constitucional 28 de agosto de 2017 (requerimiento de inaplicabilidad por inconstitucionalidad) en: https://www.tribunalconstitucional.cl/ver2.php?id=3515 [fecha de consulta: 1 de noviembre de 2018]. 
